\title{
Board 114: Developing a Model of Disciplinary Literacy Instruction for K-12 Engineering Education: Comparing the Literacy Practices of Electrical and Mechanical Engineers (Fundamental)
}

\section{Theresa Green, Utah State University - Engineering Education}

Theresa Green is a graduate student at Utah State University pursuing a PhD in Engineering Education. Her research interests include K-12 STEM integration and improving diversity and inclusion in engineering.

Dr. Angela Minichiello P.E., Utah State University

Angela Minichiello is an assistant professor in the Department of Engineering Education at Utah State University (USU) and a registered professional mechanical engineer. Her research examines issues of access, diversity, and inclusivity in engineering education. In particular, she is interested in engineering identity, problem-solving, and the intersections of online learning and alternative pathways for adult, nontraditional, and veteran undergraduates in engineering.

Dr. Amy Wilson-Lopez, Utah State University, Teacher Education and Leadership

Amy Wilson-Lopez is an associate professor at Utah State University who studies culturally responsive engineering and literacy-infused engineering with linguistically diverse students. 


\section{Board 114: Developing a Model of Disciplinary Literacy Instruction for K-12 Engineering Education: Comparing the Literacy Practices of Electrical and Mechanical Engineers (Fundamental)}

\section{Theresa Green, Utah State University - Engineering Education}

Theresa Green is a graduate student at Utah State University pursuing a PhD in Engineering Education. Her research interests include K-12 STEM integration and improving diversity and inclusion in engineering.

Dr. Angela Minichiello P.E., Utah State University

Angela Minichiello is an assistant professor in the Department of Engineering Education at Utah State University (USU) and a registered professional mechanical engineer. Her research examines issues of access, diversity, and inclusivity in engineering education. In particular, she is interested in engineering identity, problem-solving, and the intersections of online learning and alternative pathways for adult, nontraditional, and veteran undergraduates in engineering.

Dr. Amy Wilson-Lopez, Utah State University, Teacher Education and Leadership

Amy Wilson-Lopez is an associate professor at Utah State University who studies culturally responsive engineering and literacy-infused engineering with linguistically diverse students. 


\section{Developing a Model of Disciplinary Literacy Instruction for K-12 Engineering Education: Comparing the Literacy Practices of Electrical and Mechanical Engineers (Fundamental)}

\section{Introduction}

In spite of efforts to diversify the engineering workforce, the profession remains largely dominated by White, male engineers [1]. Better approaches are needed to attract and retain underrepresented groups to science, technology, engineering, and mathematics (STEM) careers, such as engineering.

One literacy-based approach that has been shown to provide effective instruction for K-12 students generally, and students from underrepresented groups specifically, is Disciplinary Literacy Instruction (DLI). DLI utilizes knowledge of the ways advanced practitioners read, interpret, and generate discipline-specific content in their professional environment to apprentice students in that field. Models of DLI teach students how to use the literacy practices, including disciplinary specific text genres, interpretive and evaluative frameworks, and socially situated activities, that are commonly employed by experts in a discipline [2]. In other disciplines [3]-[6], DLI models have been shown to aid teachers in making high quality, discipline-specific content accessible to all students, including those from groups (i.e., racial and ethnic minorities and women) that, historically, have been underrepresented in STEM fields. This paper describes findings from comparative case study research that seeks to identify literacy practices that are used by expert engineers across a range of engineering disciplines. These literacy practices will be used to inform the development of a general model of DLI in engineering that can be employed by teachers to support K-12 and undergraduate engineering education.

\section{Overview of DLI}

Disciplinary Literacy Instruction has been shown to improve student performance in academic subjects such as history [6] and science [3]. In addition, research has demonstrated that increases in student performance that are achieved as a result of DLI can be larger for those from underrepresented groups [7], [8]. Thus, DLI is a promising approach to reduce literacy-based barriers that can prevent underrepresented students, in particular, from pursuing engineering academic pathways and careers.

Commonly, researchers of DLI investigate ways to incorporate authentic literacy practices used by professionals into curricular models for K-12 education. The term literacy practice is derived from the term literacy event. Literacy events are defined by Heath [9] as "occasions in which written language is integral to the nature of participants' interactions and their interpretive processes and strategies" (p. 50). Drawing upon Heath's work, Street [10] then stated that literacy practices are the patterned types of literacy events that social groups engage in when solving problems or achieving common goals. Literacy practices thus incorporate the particular genres of texts that members of a social group read and write, the frameworks used to interpret and evaluate these texts, and the social practices in which the textual genres are situated. For example, researchers of DLI in history have found that historians engage in literacy practices such as contextualizing, sourcing, and corroborating [11], [12] when reading and evaluating 
primary source documents. We conceptualize engineering literacy practices in layers, where the discipline-specific practices (e.g. genres) are on the bottom layer while the more general engineering literacy practices (e.g. situated social activities) are on the top layer. Figure 1 demonstrates this vision of layered literacy practices. We envision that engineers working in a specific sub-discipline of engineering work with textual genres that closely reflect the work done in their discipline. These genres then inform the frameworks they use to analyze and interpret them, which in turn comprise the set of situated social activities in which the engineers are engaged.

More broad across disciplines

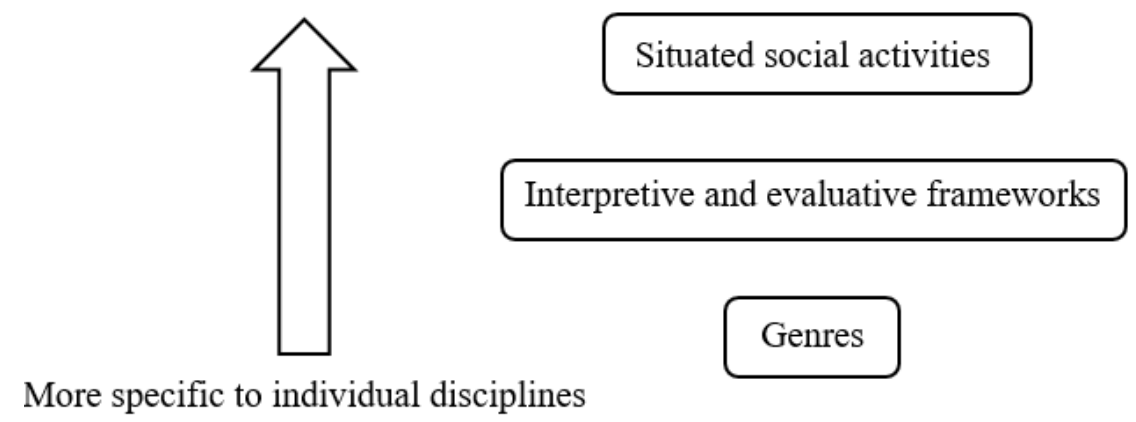

Figure 1: Illustration of how engineering literacy practices can be viewed in layers.

The purpose of this paper is to synthesize engineering literacy practices for use in the general DLI model in engineering by comparing and contrasting disciplinary specific literacy practices across two of the largest engineering sub-disciplines, mechanical and electrical engineering, using a comparative case study approach. Constant comparative analytic techniques are used to develop a set of common literacy practices used by engineers that can be translated into educational materials for K-12 engineering education. More broadly, findings from the current study will be combined with literacy practices obtained from other engineering disciplines (i.e., biological and civil engineering) to produce a robust model of DLI in engineering for K-12 education. Additionally, we will produce educational materials for post-secondary engineering education (e.g., electrical engineering education, mechanical engineering education) based on literacy practices deemed to be disciplinary-specific.

This study employs a comparative case study approach to investigate the literacy practices of electrical and mechanical engineers and answer the following research questions:

1. What are the literacy practices of electrical and mechanical engineers?

2. How are the literacy practices of electrical and mechanical engineers similar?

3. How are the literacy practices of electrical and mechanical engineers different?

\section{Perspectives}

This study is informed by situated learning theory [13], [14] and rhetorical genre studies [15][17] where the engineering profession is considered a community of practice. Situated learning theory posits that people learn within communities of practice as they become familiar with the interpretive and evaluative frameworks and social practices that are shared within the community 
[14]. Rhetorical genre studies (RGS) complement situated learning theory through the identification and examination of textual genres that are generated by specific communities of practice [18], [19]. The common values, goals, and beliefs held by a community of practice shape the textual genres that are generated within it [16], [20], [21]. In this work, we assumed that the engineering discipline is a community of practice that uses a set of shared goals and values in the process of evaluating and solving problems. The textual genres and practices that are shaped within this community will inform the development of a general model of DLI in engineering for K-12 education and disciplinary-specific curricular materials for post-secondary engineering education. Together, these research products will provide K-16 students authentic exposure to and instruction in the practices used by professional engineers in the context of their work environments.

\section{Methodology}

This study uses a qualitative research approach and a multiple, comparative case study design [22]. A comparative case study seeks to identify and contrast how a particular phenomenon manifests in different situations or contexts [23]. For this study, we seek to understand how the phenomenon of literacy practices manifests across two disciplines of engineering: electrical and mechanical. A comparative case study design allowed us to identify commonalities and differences in the literacy practices among the two disciplines.

\section{Participants}

In this comparative case study, we generated qualitative data with two electrical and two mechanical engineers over a period of 1.5 years in accordance with a human research subjects protocol that was approved by our university's Institutional Review Board. During recruitment, we required that each engineer who was selected for participation had been practicing in industry for a minimum of five years. To enhance ecological validity, we also required that each participant was employed at a different company. Furthermore, we required that participants were recommended for participation by their supervisors based on their reputations for being effective communicators and problem solvers in the workplace. Three participants were White males and one was a White female. To protect participant anonymity, we reported all data using gender-neutral pseudonyms. Table 1 provides a summary of the participants in this study, including their discipline (electrical or mechanical), specialization, and work focus.

Table 1. Summary of the participants in this study.

\begin{tabular}{|c|c|c|c|}
\hline Engineering discipline & Pseudonym & Specialization & Work focus \\
\hline \multirow[t]{2}{*}{ Electrical } & Alex & Software development & $\begin{array}{l}\text { Conceptual development and field } \\
\text { support }\end{array}$ \\
\hline & Bailey & $\begin{array}{l}\text { Hardware design and } \\
\text { testing }\end{array}$ & Testing and field support \\
\hline \multirow[t]{2}{*}{ Mechanical } & Brady & Analysis and design & Conceptual and detailed product design \\
\hline & Kelly & Process development & Management \\
\hline
\end{tabular}


The positions held by these engineers and the work done in their roles represent several phases within the engineering product development cycle (e.g., concept development, design, testing, support) as well as management. Thus, the data collected from these engineers provided insights not only into the literacy practices use across sub-disciplines of engineering, but also into the literacy practices that are used across stages of the engineering design process and will help generate a robust model of DLI in engineering.

\section{Data Sources and Analysis}

We generated data with each engineer in the form of written field notes of observation sessions, transcripts from audio and video recorded semi-structured interviews and think-aloud protocols, and written logs of literacy practices that were kept by the engineers. Observation sessions lasted two hours each and were conducted at each engineer's workplace twice per month over the course of six to seven months. Semi-structured interviews and think-aloud protocols lasted 60-90 minutes each and were conducted once per month at a time and place of each engineer's choosing. Engineers used the literacy logs to document the texts they read and wrote during work hours in between the observation and interview sessions. We periodically collected information from the engineers' logs by taking digital images of the logs and by asking the engineers to read through their logs and describe the texts they read and wrote that week that they felt were most important to their work. At the end of the six-month data collection period with each engineer, we collected her or his log for use as artifact data.

To prepare the observation field notes for coding, we segmented them into "meaningful analytical units" [23, p. 571] based on how the engineers engaged with different texts. Each time the engineer read or wrote a different text, a new segment was created and labeled with whether the engineer read or wrote the text. The text was then numbered to keep record of how many texts the engineer read or wrote during that observation. Table 2 provides a summary of the rate in which engineer engaged with different texts during a two-hour observation of a typical work day.

Table 2. Maximum and minimum numbers of read/write segments engineers engaged with during a two-hour observation of their typical work.

\begin{tabular}{lcc}
\hline & Number of Read/Write Segments per Observation \\
\hline & Maximum & Minimum \\
Alex & 65 & 22 \\
Bailey & 86 & 12 \\
Brady & 91 & 21 \\
Kelly & 80 & 40 \\
\hline
\end{tabular}

We used constant comparative analysis (CCA) techniques [25] to generate codes from the data sources. CCA was used to generate codes and themes that are grounded in the data [25]. Initial codes were generated in each of five categories for the textual genres engineers engaged with based on ideas from RGS, including authorship, form of representation, genre, physicality, and 
purpose. Codes for electrical and mechanical engineers were iteratively refined and compiled into a single codebook. The codebook forms the basis for future coding and is revised as new information is found while coding new observations. To ensure that the codes identified by the research team accurately reflect the kinds of practices used by the participants, two practicing engineers (one mechanical, one electrical) reviewed and provided feedback on the codebook. The codes were then revised based on their feedback.

Next, the codes were then compared within the group (e.g. among the electrical engineers) and across the groups (e.g. between the electrical and mechanical engineers). We first conducted a within-group CCA to determine the literacy practices and frameworks that were specific to each discipline (i.e., electrical and mechanical engineering). We then conducted a cross-group CCA to identify commonalities and differences between the literacy practices used by the mechanical and electrical engineers. The practices and frameworks identified from these analyses will be used in subsequent work to inform the general model of DLI in engineering.

\section{Findings}

To answer research question 1 , we identified the textual genres and literacy practice used by the engineers. To answer research questions 2 and 3, we compared and contrasted the genres and literacy practices across the engineering disciplines.

\section{Genres}

Across both electrical and mechanical engineers, we observed a total of 29 different textual genres used by the engineers. The 16 most common genres are shown in Table 3 in the Appendix.

Of the 16 most common genres, we found that seven genres were common genres used by both the electrical and mechanical engineers. These included email, instant messaging, file directories, personal notes, schedules, technical texts, and test results. The remaining nine genres were disciplinary specific genres; two disciplinary specific genres were used only by mechanical engineers (i.e., computer-aided design (CAD) model and human resources) and seven were used only by electrical engineers (i.e., code, code output, compiler error, device configuration software, discussion board, function definition, and manual).

For example, we found that code and code output genres were discipline specific genres frequently used by Alex, the electrical engineer specializing in software. Alex read, wrote, debugged, and evaluated code and code output that provided functionality to the company's main product line. Bailey, the electrical engineer that specialized in hardware, often consulted manuals to read procedural instructions on how to build electrical systems such as wiring harnesses or how to run a test on a motorized system.

Additionally, we found that the genres of $C A D$ model and human resources documents were specific to the mechanical engineering discipline. Brady, the mechanical engineer specializing in analysis and design, often consulted 3D CAD models of the mechanical systems their company developed and tested. Brady also used analysis (i.e., finite-element modeling (FEM)) and design (i.e. CAD) software to perform structural analyses and to evaluate design effectiveness. Kelly, 
the mechanical engineer that was in a process management role, consulted and evaluated human resource documents (e.g., interview protocols and resumes) in order to prioritize and evaluate company documents to improve the efficiency and documentation of the company's engineering processes. Because Kelly was the only engineer having a work focus in management, Kelly's use of the human resources documents may be more reflective of their management role within the company rather than their role as a mechanical engineer.

Last, we found seven genres to be common genres used by both mechanical and electrical engineers who were employed at different levels in the company at different stages of product development. For example, both sets of engineers engaged in different forms of text-based communication with other engineers within their company through email and instant messaging (e.g. Skype, Jabber, etc.) during the context of their daily work. All four engineers also took their own form of personal notes to capture information about a task they were working on without intending for those notes to be shared with others. They also all engaged with test results in different forms (e.g. computer test results, results from a motor test, data obtained from fatigue testing, results from material specification testing). All four engineers also read technical texts (e.g., part drawings, failure analysis documents, descriptions of how a computer code works) to help them make design or testing decisions, learn technical information, or compare information across different texts.

\section{Frameworks}

In total we identified six frameworks used to interpret texts and 12 frameworks used to evaluate texts (Tables 4 and 5 in the Appendix). As compared to the genres, most frameworks were used by engineers from both disciplines. For example, all 12 evaluative frameworks were used by both the electrical and mechanical engineers. Of the six interpretive frameworks identified, four were used by engineers in both disciplines and two were used only by the mechanical engineers.

For example, one common interpretive framework (Table 4) that was used by both sets of engineers was emphasizing the importance of using and documenting design histories. This interpretive framework was used to guide the engineers' design process to see if the same design, fix, or process had been done before, so to not redo work that had already been done. Design histories also provided engineers with a "point of departure" from which to begin working on a new task based on what had been done previously. Similarly, all of the evaluative frameworks identified were common across both disciplines of engineers (Table 5). For example, the evaluative framework of efficiency was used by the engineers to evaluate what priority a task had relative to other tasks, or if certain documentation information was redundant.

Results show that there were two interpretive frameworks that differed between the groups of engineers. For example, the interpretive framework (Table 4) of signaling was found specifically in the data from the mechanical engineers and not from the electrical engineers. Signaling refers to using colored text in a document or drawing to convey meaning to the reader. For example, while reviewing and annotating a technical drawing, Brady stated in an interview, "if I put red notes, that means they have to be implemented in my opinion. If I write something in pencil, that's a suggestion." Additionally, the mechanical engineers were found to evaluate the interchangeability of the content of a document. For example, the engineer specializing in process management discussed their thought process as they evaluated whether a certain 
adhesive would meet the same requirements as a completely different adhesive with a different specification (Table 5).

\section{Socially Situated Activities}

As shown in Table 6 in the Appendix, we identified six socially situated activities. Similar to the evaluative frameworks, we found that all of the socially situated activities we identified were used by engineers from both disciplines. For example, these activities include troubleshooting root cause(s) of failure and multimodal communication as shown in Figure 2.

In discerning relationships between the three layers of literacy practices (i.e., genres, frameworks, and socially situated activities) shown in Figure 2, we noticed two things. First, the genres that an engineer chose to engage with were mediated by the interpretive or evaluative framework they were utilizing as they worked. For example, as shown in Figure 2, an engineer may be operating under the need for efficiency in terms of time, cost, or effort. When making a selection of which method to communicate with someone about this work, the engineer might choose between email or an instant message as the mode of communication (i.e., genre), depending on the urgency or importance of their request or inquiry, the context of the work, and the relationship held with the other person. Next, a common social practice, using multimodal communication strategies, then developed as a result of the engineer's frequent requirement for efficiency (framework) and resultant choice of genres for which to achieve that purpose. 


\section{Situated social activities}

- Defining/understanding/translating customer/user needs

- Documenting informally "as you go"

- Information gathering across multiple, multimodal texts

- Multimodal communication - text chat, email, historical documentation, formal documentation

- Professional knowledge building

- Revising based on feedback, in light of more recent information, etc.

- Troubleshooting root cause(s) of failure

\section{Frameworks}

Interpretive frameworks

Evaluative frameworks

- Credibility

- History - what has been done before

- Interchangeability*

- "Point of Departure"

- Signaling*

- Specificity, purpose, based on a need for precise information
- Accuracy

- Conciseness, simplicity, clarity

- Consistency/alignment

- Design requirements

- Efficiency (time, cost, effort)

- Extent to which text is driven by data

- Extent to which text is prepared with the appropriate expertise/approved by the appropriate stakeholders

- Priority of importance

- Repeatability

- Safety requirements

- Searchability

- Timeliness, currency, up to date

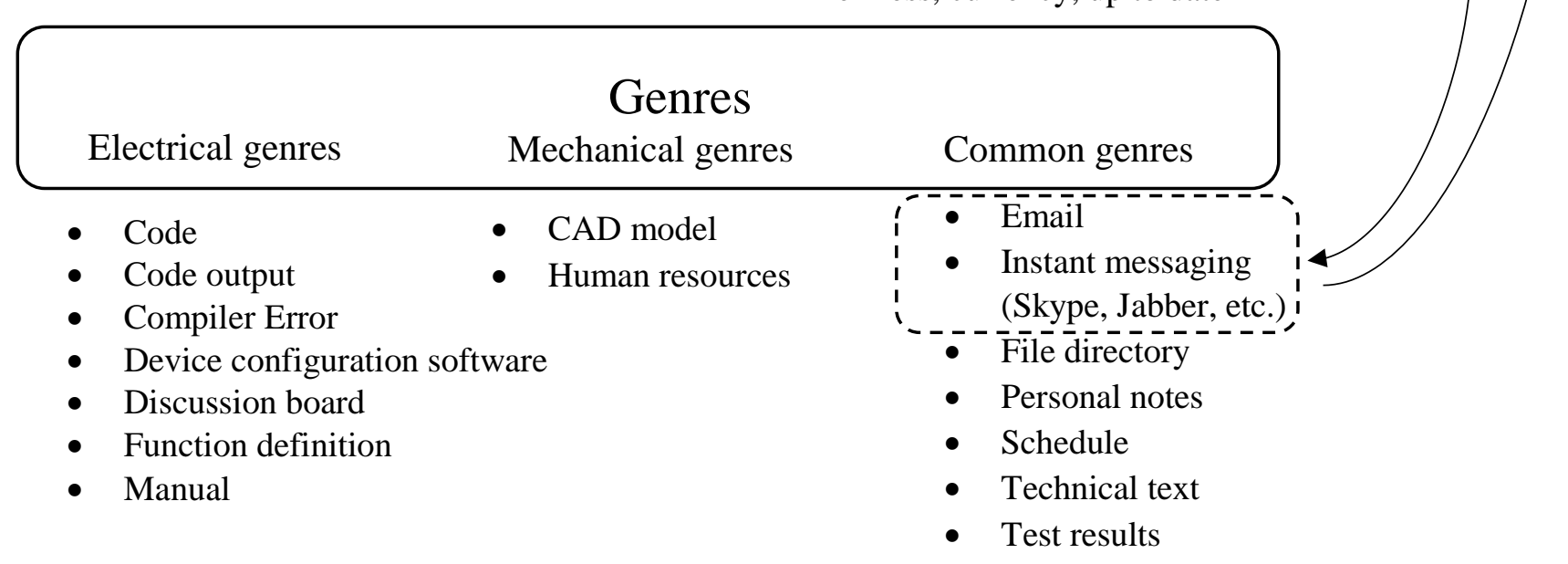

Figure 2: Visual representation of genres found within frameworks that are situated within social activities of the engineers.

* Mechanical only 


\section{Discussion}

This study provides foundational knowledge that will lead to a general model of DLI in engineering. Before describing the implications of this study specifically, we first turn to other disciplines to describe how they used studies with experts in each discipline in order to develop models of disciplinary literacy. Models of disciplinary literacy [e.g., 28, 11, 29] are developed, first, through determining the interpretive frameworks that expert practitioners in each discipline use as they read and write discipline-specific texts. These interpretive frameworks are then shared with in-service and pre-service teachers. Teachers then "think aloud" as they read texts within each discipline, in order to model for students how an expert in that discipline might think as they read [30]. After students have had an opportunity to learn how practitioners in each discipline interpret a text, students themselves gain practice in using similar interpretive frameworks through scaffolded experiences (e.g., discussion prompts and annotation exercises that encourage students to evaluate a text like an engineer would evaluate a text).

This model of DLI can be modified to be developmentally appropriate and culturally responsive in the context of education with diverse K-12 students as well. For example, we found that engineers from both disciplines interpreted and evaluated test results in order to determine whether a product was ready to be shared with a client and/or what modifications had to be made and tested first. We imagine a situation in which upper elementary students develop prototypes in order to help a client - for example, parachute designs that could safely help a "candy bomber" deliver candy to children [26] — and develop and evaluate a plan for testing the parachutes. In keeping with the Next Generation Science Standards, which emphasize "planning and carrying out fair tests in which variables are controlled and failure points are considered," (35 ETS1-3) [27], the elementary students could create a testing plan (a genre). Using think-alouds and discussion prompts, the teacher could model for students how to evaluate that genre using the discipline-specific evaluative frameworks generated from this study. For example, the elementary students might consider statements such as, "I believe the results from this test would be repeatable (or not) when the candy bomber dropped the parachutes because..." "I believe this prototype design meets our stated priorities (or not) because..." In this case, this type of instruction approximates an authentic socially situated activity (e.g., translating a customer's needs to deliver candy into a product); includes authentic engineering genres (a testing plan); and provides students with practice in applying evaluative frameworks (repeatability).

Though this example reflects how DLI might be applied in upper elementary school, scholars have asserted that DLI can be appropriate even for students as young as Kindergartners [31], as long as teachers use developmentally appropriate practices (e.g., reading simple texts aloud to students, letting students dictate their ideas to teachers and they can co-write the ideas with the students). In all, we intend from the findings of this study to generate a set of principles that teachers can consider when they are creating learning environments in which their students engage in engineering. Teachers might engage students in socially-situated activities that are similar in purpose to those of engineers. Within this context, they can provide their students with developmentally-appropriate genres that are similar to those engineers read; and they can model for their students how to evaluate those genres like engineers evaluate texts. On a pragmatic level, ultimately, we also intend for this project to result in instructional materials, including sets 
of texts for students and guiding teachers' materials (e.g., discussion prompts) that might support student engagement with those texts in the context of authentic tasks.

In addition to supporting practices in K-12 environments, we believe that the literacy practices and interactions depicted in this model of DLI that are specific to each discipline can also be used to support curricular development and authentic instructional practices (e.g., problem based learning) in disciplinary specific undergraduate engineering education (i.e., undergraduate programs in mechanical and electrical engineering). For example, mechanical engineering students could be asked to evaluate whether or not a test procedure meets the standards for which it was written, or how to determine whether or not sufficient information was given in test plan documentation such that the test could be performed. Students would learn how to interpret pertinent information from technical standards and apply it to a company-specific product. Electrical engineering students could be asked to reconstruct a wiring harness from a wiring diagram that was created by someone else. This would give students the opportunity to determine whether or not sufficient information to build the part was present on the diagram and, if not, the students could be required to explain what elements they would include if they were to revise the wiring diagram.

In summary, our study follows previous work in disciplinary literacy, in which scholars first studied how advanced practitioners interpreted texts, and then worked with teachers to develop instructional materials that would teach students how to interpret texts in similar ways. This study reports on the first step toward this vision, specifically, an identification of advanced practitioners' socially-situated activities and interpretive frameworks, and identification of their implications for classroom instruction.

\section{Conclusion}

In conclusion, literacy practices found to be common across engineering disciplines will be used to develop a general model of DLI in engineering. Engineering DLI will provide diverse K-12 students a range of new opportunities for exploring and applying new knowledge within the context of authentic engineering work. By making a general model of DLI in engineering widely available to teachers and practitioners, all students will have the potential to access high-quality curricular materials based on authentic engineering literacy practices. We envision that disciplinary literacy instruction will be embedded within engineering challenges and/or contexts that students find relevant and meaningful to further increase their interest and engagement. Through DLI, we hope to diversify the engineering workforce by making the (oftentimes implicit) norms of engineering more explicit, in the contexts of engineering tasks that are relevant to students.

\section{Acknowledgements}

Support for this work is provided by the National Science Foundation under Award No. EEC 1664228. Any opinions, findings, conclusions, or recommendations expressed in this material are those of the author(s) and do not necessarily reflect the views of the National Science Foundation. We would like to thank our engineer participants and disciplinary consultants for their time and effort in supporting this project.

This material is based upon work while serving at the National Science Foundation. 


\section{References}

[1] National Science Board, "Science and Engineering Indicators," Arlington, VA: National Science Foundation (NSB-2016-1), 2016.

[2] R. Schoenbach, C. Greenleaf, and L. Murphy, Reading for understanding: How reading apprenticeship improves disciplinary learning in secondary and college classrooms, 2nd ed. San Francisco, CA: WestEd, 2012.

[3] G. N. Cervetti and P. D. Pearson, "Reading, Writing, and Thinking Like a Scientist," Journal of Adolescent \& Adult Literacy, vol. 55, no. 7, pp. 580-586, Apr. 2012.

[4] A. M. Hillman, "A literature review on disciplinary literacy: How do secondary teachers apprentice students into mathematical literacy?," Journal of Adolescent \& Adult Literacy, vol. 57, pp. 397-406, 2014.

[5] P. Smagorinsky, "Disciplinary literacy in English Language Arts," Journal of Adolescent \& Adult Literacy, vol. 59, pp. 141-146, 2015.

[6] S. Wineburg and A. Reisman, "Disciplinary literacy in history: A toolkit for digital citizenship," Journal of Adolescent and Adult Literacy, vol. 58, pp. 636-639, 2015.

[7] G. N. Cervetti, J. Barber, R. Dorph, P. D. Pearson, and P. G. Goldschmidt, "The impact of an integrated approach to science and literacy in elementary school classrooms," Journal of Research in Science Teaching, vol. 49, no. 5, pp. 631-658, 2012.

[8] R. Lara-Alecio, F. Tong, B. J. Irby, C. Guerrero, M. Heurta, and Y. Fan, "The effect of an instructional intervention on middle school English learners' science and English reading achievement," Journal of Research in Science Teaching, vol. 49, pp. 987-1011, 2012.

[9] S. B. Heath, "What no bedtime story means: Narrative skills at home and school," Language in Society, vol. 11, pp. 49-76, 1982.

[10] B. V. Street, "Literacy events and literacy practices: Theory and practice in the New Literacy Studies," in Mutilingual literacies: Reading and writing different worlds, K. Jones and M. Martin-Jones, Eds. Philadelphia: John Benjamins Publishing Company, 2000, pp. 17-29.

[11] S. Wineburg, "Historical Problem Solving: A Study of the Cognitive Processes Used in the Evaluation of Documentary and Pictorial Evidence," Journal of Educational Psychology, vol. 83, no. 1, pp. 73-87, 1991.

[12] S. Wineburg, "Reading Abraham Lincoln: An expert/expert study in the interpretation of historical texts," Cognitive Science, vol. 22, no. 3, pp. 319-322, 1998.

[13] J. Lave, "Situating Learning in Communities of Practice," in Perspectives on Socially Shared Cognition, vol. 2, L. B. Resnick, J. M. Levine, and S. D. Teasley, Eds. Washington, D.C.: American Psychological Association, 1991, pp. 63-82.

[14] J. Lave and E. Wenger, Situated learning: Legitimate peripheral participation. New York, NY: Cambridge University Press, 1991.

[15] A. Devitt, Writing genres. Carbondale, IL: Southern Illinois University Press, 2004.

[16] C. Miller, "Genre as social action," Quarterly Journal of Speech, vol. 70, pp. 151-167, 1984. 
[17] C. Miller, "Rhetorical community: The cultural basis of genre," in Genre and the new rhetoric, A. Freedman and P. Medway, Eds. London: Taylor and Francis, 1994, pp. 6778.

[18] N. Artemeva, "Toward a unified social theory of genre learning," Journal of Business and Technical Communication, vol. 22, pp. 160-185, 2008.

[19] N. Artemeva, "Stories of becoming: A study of novice engineers learning genres of their profession," in Genre in a changing world, C. Bazerman, A. Bonini, and D. Figueiredo, Eds. West Lafayette, IN: Parlor Press, 2009, pp. 158-178.

[20] C. Bazerman, Shaping written knowledge: The genre and activity of the experimental article in science. Madison, WI: University of Wisconsin Press, 1988.

[21] A. Devitt, "Teaching critical genre awareness," in Genre in a changing world, A. Bonini and D. Figueiredo, Eds. West Lafayette, IN: Parlor Press, 2009, pp. 337-351.

[22] R. K. Yin, Case Study Research Design and Methods. Thousand Oaks, CA: Sage, 2014.

[23] R. E. Stake, Multiple case study analysis. New York: Guilford Press, 2006.

[24] R. B. Johnson and L. Christensen, Educational Research: Quantitative, Qualitative, and Mixed Approaches, 6th ed. Thousand Oaks, CA: SAGE Publications, 2017.

[25] R. Thornberg and K. Charmaz, "Grounded theory and theoretical coding," in The SAGE handbook of qualitative data analysis, U. Flitz, Ed. Los Angeles, CA: SAGE, 2014, pp. $153-169$.

[26] A. Wilson-Lopez, S. Gregory, and V. Larsen, "Reading and engineering: Elementary students' co-application of comprehension strategies and engineering design processes," Journal of Pre-College Engineering Education Research, vol. 6, no. 2, pp. 39-57, 2016.

[27] NGSS Lead States, "Next Generation Science Standards: For States, By States (3-5 ETS13), 2013.

[28] T. Shanahan and C. Shanahan, "Teaching disciplinary literacy to adolescents: Rethinking content-area literacy," Harvard Educational Review, vol. 78, no. 1, pp. 40-59, 2008.

[29] E. Rainey, "Disciplinary literacy in English language arts. Exploring the social and problem-based nature of literary reading and reasoning," Reading Research Quarterly, vol. 52, pp. 53-71, 2017.

[30] R. Schoenbach, C. Greenleaf, and L. Murphy, Reading for understanding: How reading apprenticeship improves disciplinary learning in secondary and college classrooms, 2nd ed. San Francisco, CA: WestEd, 2012.

[31] C. Shanahan and T. Shanahan, "Does disciplinary literacy have a place in elementary school?" The Reading Teacher, vol.67, no. 8, pp. 636-639, 2014. 


\section{Appendix}

Table 3. The 16 most common genres used by the electrical and mechanical engineers (in alphabetical order).

\begin{tabular}{ll}
\hline \multicolumn{1}{c}{ Genres of texts } & \multicolumn{1}{c}{ Definition } \\
\hline CAD model & $\begin{array}{l}\text { Two- or three-dimensional (2D or 3D) representation of a physical } \\
\text { object that is created, modified, analyzed and documented using } \\
\text { specialized graphical computer programs as an alternative to manual } \\
\text { drafting and physical prototyping. }\end{array}$ \\
Code & $\begin{array}{l}\text { Symbolic arrangement of instructions in a computer program. } \\
\text { Code output }\end{array}$ \\
Results returned by a computer after processing code. \\
Compiler error \\
programmer that the code has an error and will not run. Used as a \\
debugging tool. \\
A software package that enables the user to adjust system settings and \\
resources (e.g., motherboard settings, BIOS, bus speeds, COM ports) in \\
order to tune system performance or to enable it to perform a particular \\
function. \\
Responses to a posed question or problem. \\
Discussion board \\
Email
\end{tabular}


Table 4. Interpretive frameworks identified for electrical and mechanical engineers (in alphabetical order).

\begin{tabular}{|c|c|c|}
\hline \multirow[t]{2}{*}{ Interpretive frameworks } & \multicolumn{2}{|c|}{ Representative data excerpts } \\
\hline & Electrical & Mechanical \\
\hline Credibility & $\begin{array}{l}\text { "And so, I wouldn't discount } \\
\text { information based on where it } \\
\text { came from, it's more whether it's } \\
\text { fitting, whether it seems to be } \\
\text { fitting the information that I feel } \\
\text { that I need. And so that's when I } \\
\text { judge the content. It's more based } \\
\text { on what's there rather than where } \\
\text { it's coming from I would say." }\end{array}$ & $\begin{array}{l}\text { "So, I was just checking to see, did } \\
\text { I have access to run the report? } \\
\text { And when I ran the report, what } \\
\text { did it look like and had somebody } \\
\text { manipulated the report to get it to } \\
\text { this state? I was just looking to see } \\
\text { if I could do my own report so that } \\
\text { I could get my own data and how } \\
\text { long it would take." }\end{array}$ \\
\hline $\begin{array}{l}\text { History - what has been done } \\
\text { before }\end{array}$ & $\begin{array}{l}\text { "One of the reasons that we're } \\
\text { generating this is, it really becomes } \\
\text { part of design history for the } \\
\text { product itself. And so later on as } \\
\text { people ask what kind of tests have } \\
\text { been done, it provides some of } \\
\text { those answers, these are the tests } \\
\text { we did on it, and this is why we did } \\
\text { them, and this is in effect what it } \\
\text { means." }\end{array}$ & $\begin{array}{l}\text { "So if I'm doing, there's not a lot, } \\
\text { if ever, we do anything that's } \\
\text { totally unique and new. So, call } \\
\text { that one of the fundamental things } \\
\text { of engineering is, see what has } \\
\text { been done before. And even if you } \\
\text { did it before, you can't remember } \\
\text { everything. So whenever doing } \\
\text { something similar, I refer back to } \\
\text { old reports." }\end{array}$ \\
\hline $\begin{array}{l}\text { Interchangeability, compare } \\
\text { and contrast }\end{array}$ & Framework not found & $\begin{array}{l}\text { "So, if I have a specification for, } \\
\text { I'm gonna use generically } \\
\text { adhesive, adhesive here and I have } \\
\text { a specification that's completely } \\
\text { different, different part number, } \\
\text { different adhesive. And adhesive } \\
\text { that I want to use either as an } \\
\text { alternative or instead of, often we } \\
\text { will compare the two } \\
\text { specifications. And so, we have a } \\
\text { process that we do that. We'll } \\
\text { compare the requirements and it'll } \\
\text { be like, you know, chemistry is one } \\
\text { of the requirements for the } \\
\text { chemistries. Where the } \\
\text { requirements for processing, shelf } \\
\text { life, transportation, storage. So, } \\
\text { we'll compare specs for }\end{array}$ \\
\hline
\end{tabular}


interchangeability or can one can be used as an alternate for the other."

"Point of Departure", starting from a known point (not necessarily the beginning) based on previous experience (with a given text)

Signaling - usually using colored text, red means "do it", pencil means ...
"Looking at those sources to see what we saw in past tests, what our expectations are, and then what is it that the motor we're looking at is producing...the relationship between all of those, old data expectations and new data."

Framework not found
"So, there's usually a point of departure, we're going to build something and it's going to be based upon something we've already done. So, history is really huge in our business."
Specificity, purpose, based on a need for precise information
"And I wanted to make sure that we either had a spec for the actuator itself that we're driving, or, and/or, that we're testing it as a combination of this test we're performing that we're also verifying either their temperature spec, or if they don't give one, that it still operates within that specification, within our specification. And in the one document it actually didn't contain min and max temperature, even within either of those documents. The other one gave a min and max temperature that matches our specification."
"So, if I put red notes, that means they have to be implemented in my opinion. If I write something in pencil, that's a suggestion. And then when the editor is going back he'll, with a green highlighter, highlight the ones that are done. Or yellow the ones that can't be done and so on."

"And I can tell that a code is that program, but I will have no idea what that work represents. And so that's when I'll talk to somebody, either the person that's issuing the work order or the person that's working to that particular work order. Like, "You're working on this work order and the code description doesn't tell me anything, what specifically are you doing?" So, I do that a lot just to find out what people in my organization are doing specifically." 
Table 5. Evaluative frameworks identified for the electrical and mechanical engineers (in alphabetical order).

\begin{tabular}{|c|c|c|}
\hline \multirow[t]{2}{*}{ Evaluative frameworks } & \multicolumn{2}{|c|}{ Representative data excerpts } \\
\hline & Electrical & Mechanical \\
\hline Accuracy & $\begin{array}{l}\text { "So that we could, that was one of } \\
\text { our first steps in assessing, once we } \\
\text { had that test procedure, of whether } \\
\text { we were getting uniform data from } \\
\text { each motor to where we thought we } \\
\text { were testing it accurately. Because } \\
\text { the idea was, you know, each motor } \\
\text { under the same test should } \\
\text { essentially produce the same result. } \\
\text { And they were, you know, close } \\
\text { and near." }\end{array}$ & $\begin{array}{l}\text { Brady: And so, I've thought about this a } \\
\text { few times. What's it take to get an A on } \\
\text { a test? What percent do you have to get } \\
\text { right? } \\
\text { Interviewer: } 94 \% \text {. } \\
\text { Brady: So, what if we got } 94 \% \text { of these } \\
\text { details right? } \\
\text { Interviewer: You could still kill } \\
\text { somebody. } \\
\text { Brady: So, we've got to be in the } 99.9 \% \\
\text { area to try and do good work. And } \\
\text { sometimes that's hard to communicate } \\
\text { with people outside of the engineering, } \\
\text { in other parts of business, like, "We're } \\
\text { doing our best." }\end{array}$ \\
\hline $\begin{array}{l}\text { Conciseness, simplicity, } \\
\text { clarity, efficient use of } \\
\text { words }\end{array}$ & $\begin{array}{l}\text { "And so, it's pulling information } \\
\text { from various sources and just sort } \\
\text { of trying to organize it in a way that } \\
\text { you can more concisely go through } \\
\text { it." }\end{array}$ & $\begin{array}{l}\text { "But it was learning how, "A } \\
\text { requirement is not a requirement unless } \\
\text { it's defined, approved, and released." So } \\
\text { that's sort of the back bone of this. Is, if } \\
\text { you were going to be working to a piece } \\
\text { of engineering, then that piece of } \\
\text { engineering has to have been created, it } \\
\text { has to have been approved by whoever, } \\
\text { and it has to be released so that it's } \\
\text { accessible, right? And so that's this } \\
\text { structure that I'm talking about where } \\
\text { everything has to be clear, concise, and } \\
\text { valid." }\end{array}$ \\
\hline $\begin{array}{l}\text { Consistency/alignment } \\
\text { within and across texts }\end{array}$ & $\begin{array}{l}\text { "Generally, once I've done one } \\
\text { thing I try to keep the format the } \\
\text { same moving forward unless } \\
\text { somebody asks for something } \\
\text { specifically. Mostly just to keep } \\
\text { things a little bit more consistent } \\
\text { and easy." }\end{array}$ & $\begin{array}{l}\text { "...it's a manual effort to come over to } \\
\text { the Visio spreadsheet and change the } \\
\text { color on that spreadsheet. And that's } \\
\text { often where you see chAlexges when } \\
\text { you go to like close something out is, } \\
\text { they don't always match. Because you } \\
\text { got focused on the spreadsheet and you } \\
\text { forgot to keep the diagram which is a } \\
\text { visual representation in sync." }\end{array}$ \\
\hline
\end{tabular}




\begin{tabular}{ll}
\hline Design requirements (i.e. & "And the reason that we were \\
form fit function, cost, & failing the test that we were doing, \\
aesthetics) & is we were actually doing a test that \\
& was outside of the scope of our \\
design effort and that there's not a & problem with the motor, but it \\
& highlights our need for establishing \\
& better requirements, better limits up \\
& front, so that we understand where \\
& we sit, and if those requirements \\
& have a need to change, we \\
& understand where we can go before \\
& we have to do any kind of redesign \\
& if we want to achieve something \\
& that is outside of the limits that we \\
& had initially set."
\end{tabular}

Efficiency (cost, time, effort)

Extent to which text is driven by data

"Then there was looking at real time data from the motor itself, and
"There's very little that we just kind of say, "Hey, we'll do that this way just 'cause that's how we do it." Most of the requirements come from contracts or standards or other places. So, yeah trying to get things referenced appropriately."

"...it's like outlining the amount of work that is left to go into it instead of just going through piece by piece. You might not know how big your task is. So, that's why I do that." being able to see what it's currently outputting or what its current inputs are as far as voltage, what kind of current it's outputting and to see the temperatures at what it's running. So, looking at those sources to see what we saw in past tests, what our expectations are, and then what it is that the motor that we're looking at is producing."
"Normally I try to be data driven in the argument because it's a stronger position usually if I'm trying to be convincing." 


Extent to which text is
prepared with the
appropriate
expertise/approved by the
appropriate stakeholders
(consensus among
stakeholders)

Priority of importance

Repeatability, able to be replicated or executed

Safety requirements
"And then depending on which customer it's going to there's a change that has to happen where we program logic devices differently and we remove a jumper resistor that provides a static input to one of those so that it performs the action as we want it to."

"Now, that's kind of, you know, I mean we're always operating under something. Is this worth doing? And you're always operating on, on kind of like, you know, request that you get and ideas that come up. Oh yeah, is this really worth doing?"

"And now also we have the capability of understanding how we can duplicate that behavior on the bench so that we don't have to go out into a vehicle in order to be able to perform these types of tests in order to make sure that we're still capable of reaching what it that we want to reach, and if we do change that what we will need to do that."

"And to try to also note that although this titled that we're looking at in an operational failure, that it's not, there's a reason why it's an operation failure and that it's nothing that anybody needs to be scared or worried about because it's nothing that's going to cause a problem for our customers or for us, it's just something that we need to understand more about how this operates under certain circumstances."
"And so, I wanted to just walk her through what I had done so that she understood all of the different legs. And if she agreed, because we're doing this together, most of the processes are owned by HR, so I'm an engineer looking at her processes telling her what I think are failure modes. And so, it was really important that we sort of owned this together."

"I like to read it first fairly quickly and just comment on things that deserve more attention or another look later on. And some of those comments were for me to know that I needed to come back and get some more detail on something or verify."

"So, a text like this, something along the lines of, is it written clearly enough that you could get repeatable results with different people applying it?"

"A few important things about engineering are, I guess, maybe important about how I do engineering, it's being thorough and accurate. Something that weighs on my mind, especially considering the type of work that I do currently, is safety. If I miss something I would feel very badly." 
Searchability, ease of finding information

Timeliness, currency, up to date, most recent version
"The schematic I was using was a schematic that I actually built for another test, but because I'm familiar with it I know exactly where it is and where to find it. I pulled that one up so I could see the zoomed in signals that are coming in and off of [the device] so that I can know their inputs and what pins they go to, so I can know how to pin the connectors to the harnessing that I want."

"Some of those expectations is that the initial requirements document were based on requirements that are actually no longer; it's not that they they're no longer valid, but they're no longer our norm."
"Probably the big advantage of using an internet source is the searchability of it. If it is available on the internet, I would rather use the internet than a printed source. Because I can search it easily."

"And you had to stay current on the rules. That's just a discipline that I have from a previous life. So, a lot of times, and this is a discipline I would like to instill in more engineers, is anytime you do a task, the first thing that you ask yourself is, "What are the standards that apply to this task?" And then refresh yourself and make sure they're current." 
Table 6. Situated social activities in which the observed genres are embedded (in alphabetical order).

\begin{tabular}{|c|c|}
\hline $\begin{array}{l}\text { Situated social activities in which } \\
\text { genres are embedded }\end{array}$ & Representat \\
\hline & Electrical \\
\hline $\begin{array}{l}\text { Defining/understanding/translating } \\
\text { customer/user needs (i.e., problems) } \\
\text { technically (in relation to the } \\
\text { technical design) }\end{array}$ & $\begin{array}{l}\text { "And I think our, and so I think } \\
\text { that that's a big reason for our } \\
\text { success, is us engineers are } \\
\text { really in touch with the } \\
\text { customers. And relying a whole } \\
\text { lot on our marketing guys to } \\
\text { help us understand the } \\
\text { customers." }\end{array}$ \\
\hline
\end{tabular}

Documenting informally "as you go"/ as part of part/process/procedure design; documenting a design's history

Information gathering across multiple, multimodal texts

Definitions for the internet protocols for example, you can google them, and you can find them... we have, you know, a software, or we have an engineering, under engineering that's kind of like a Wikipedia or engineering kind of wiki on that one we talked about...And that's in a PDF file."
"If you wanted to change a policy or a procedure you would have a process that you would go through where you would say, "Here's the change that I want to make. Who are the stakeholders? Who are the owner, user, and independent verifier that should approve that change?" And then once I approve a change, then I implement a change. And who are the people affected in the implementation and have I thought through the full implementation?"

...while he reads the submittal document on his computer. $\mathrm{He}$ changes something in the revision history table in this document. He adds a date and the name of someone who approved some changes.

"Because I'm new to the group I'm looking at papers that we've published, conference publications that we've presented, different things like that to just kind of see, what's the current state of the union on all of these things. So, I'm reading a ton to get educated on where we've been and where we should go next." 
Multimodal communication - text chat (near real time), email

(informal), historical

documentation, formal

documentation. Based on who, context, time, efficiency

Professional knowledge building expanding who I am to be competent and capable on the job
Revising- based on feedback (customer, team), in light of more recent information from customer, tests, standards, regulations, etc.

Troubleshooting root cause(s) of failure
"I mean when somebody, when you're, when they're actually over here instead of email, see some of this could've gone via email, but you know a lot of times it's really good just one on one with people and you can write it down, you know what they're thinking."

"Yeah, it's, yeah, it's learning, yeah, a lot of it is through just, I mean part of it, a lot of the learning is Wikipedia, you know, has descriptions about certain, you know, about things...Yeah, this is actually what I've been studying this just the last few days. And this is like learning in terms of, really it's specifically learning about, well it is a whole new subject, HTTP/2."

"In this case I actually, you know, communicated with...our main guy in England that, you know, is close to the customers and brings up these problems or. And part of that communication at that stage is to try to get more information from the customer."

"And so, the key is zeroing in on what code is messed up. Where in the code is it messed up? And that's where you gotta kind of bring not only, you gotta go back and forth between the code itself so you can understand kind of what it's doing, and you go back to, you're calling it test outputs or something, you're going back to other documents or other things."
"Why did I choose IM? Because the comments weren't worth walking over and having a discussion about them. Efficiency I guess in that case. And I think he had Skyped me about the original issue."

"We get comfortable with procedures that we either were trained on initially or at some point in time you had some training and then we forget that we have to stay continually trained on procedures."

"And then I also do a fair amount of documentation on the analysis. Verify that designs meet various codes and participate in design reviews with customers."

"And the tendency with people, engineers and all people, is to say, "Oh, well here was the problem. Here's how I'm gonna fix it." Which is not a very structured approach to looking at all of the things that actually created a problem. Because often it's a whole root cause analysis. So, often if you have a root cause you might have a number of contributing causes. And so, if you solve the root cause, you might 


\begin{tabular}{ll}
\hline $\begin{array}{l}\text { miss the opportunity to solve a } \\
\text { contributing cause which would } \\
\text { become your next root cause." }\end{array}$ \\
\hline
\end{tabular}

